\title{
Machen sie den
}

\section{BVG-Check-up!}

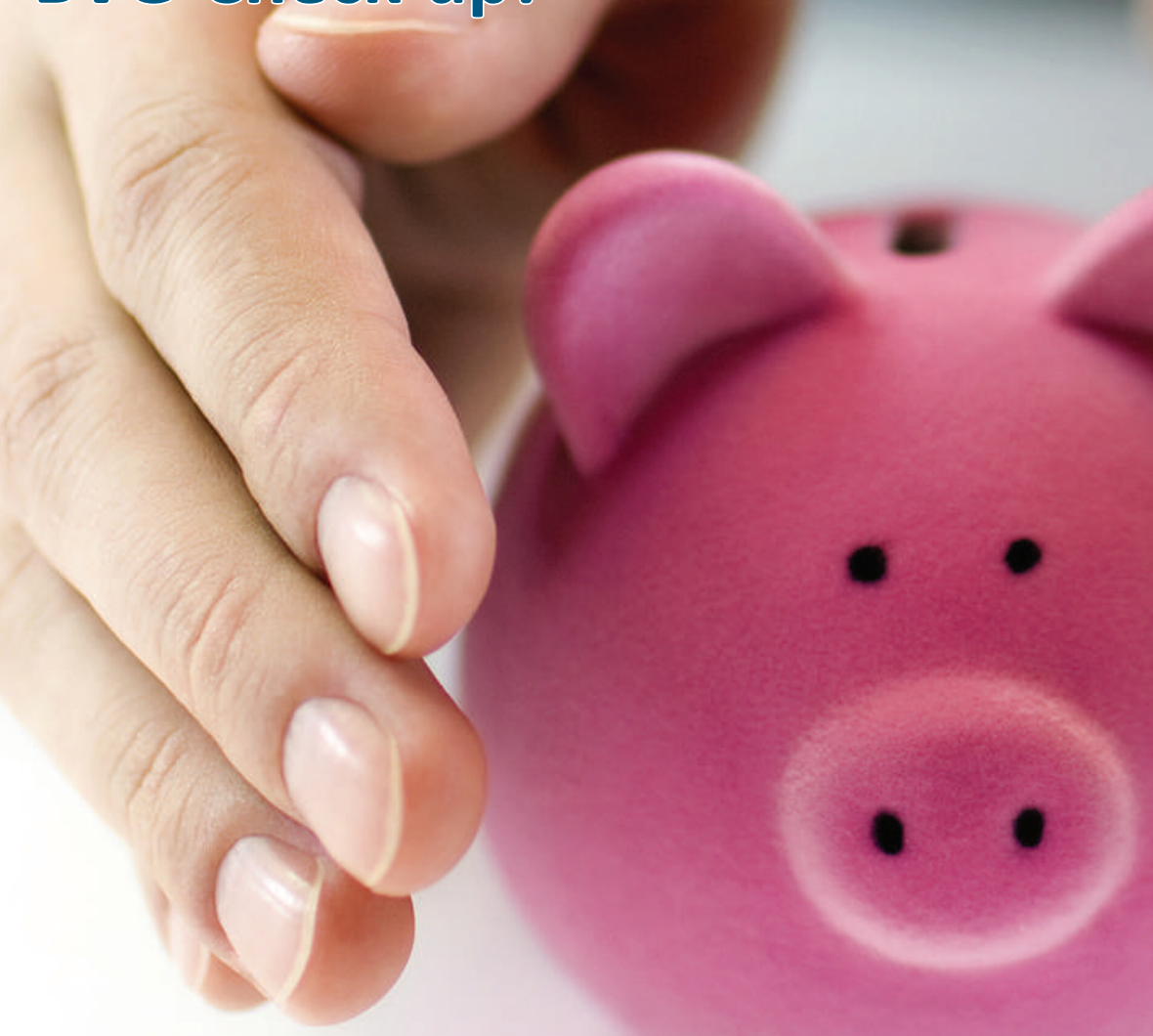

Obwohl der grösste Teil des Privatvermögens der Ärzteschaft bei einer Pensionskasse liegt, wird dieser Bereich oft vernachlässigt. Durch eine regelmässige Überprüfung, wird die gewählte Lösung an die persönliche Vorsorge- und Anlagestrategie angepasst. Ein weiteres Ziel ist es, die Steuersituation zu optimieren. Profitieren Sie dabei von unserer Dienstleistung BVG-Check-up und lassen Sie sich von einem FMH Insurance Services-Vertrauenspartner beraten.

\section{BVG-CHECK-UP}

$\square \quad$ Die berufliche Altersvorsorge ist mir wichtig und ich möchte mich unverbindlich beraten lassen. Bitte nehmen Sie mit mir Kontakt auf, um einen Termin zu vereinbaren.

$\square \quad$ Bitte senden Sie mir eine kostenlose Vergleichsofferte zu. (Bitte Kopie des aktuellen Vorsorgeausweises beilegen.)

$\square \quad$ Ich wünsche eine persönliche Beratung. Bitte rufen Sie mich an.

Vorname / Name

Adresse

\section{PLZ / Ort}

Telefon Privat / Geschäft

Beste Zeit für einen Anruf

E-Mail-Adresse

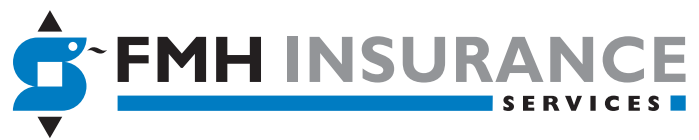

Roth Gygax \& Partner AG - Koordinationsstelle Moosstrasse 2, 3073 Gümligen Tel. 0319595000 - Fax 0319595010 mail@fmhinsurance.ch - www.fmhinsurance.ch 